УДК 37.013

DOI: 10.33184/pnpoku-2021-11-26.12

ТРАНСФОРМАЦИЯ ИНФОРМАЦИОННООБРАЗОВАТЕЛЬНОЙ СРЕДЫ В СООТВЕТСТВИИ С НОВЫМ СТАНДАРТОМ ФГОС НОО

\author{
Богомазова А. Е., \\ учитель начальных классов, \\ школа №113 им. И.И. Рыбалка, г. Уфа, Россия
}

Гурова Е. В., доцент

Башкирский государственный университет, г. Уфа, Россия

Аннотация: в статье раскрыто современное представление об информационно - образовательной среде в рамках уточняющих критериев новых ФГОС НОО. Проведен анализ современных образовательных электронных ресурсов в открытом доступе сети Интернет подходящих для использования учителями начальных классов.

Ключевые слова: информационно - образовательная среда (ИОС), электронная информационно-образовательная среда (ЭИОС), онлайн-платформы, образовательные порталы, коммуникационные платформы, интерактивные доски онлайн.

\title{
TRANSFORMATION OF THE INFORMATION AND EDUCATIONAL ENVIRONMENT IN ACCORDANCE WITH WITH THE NEW STANDARD OF THE FEDERAL STATE EDUCATIONAL STANDARD
}

Bogomazova A.E., primary school teacher I.I. Rybalka School No.113, Ufa,Russia Gurova E.V., Associate Professor, Bashkir State University, Ufa, Russia

Abstract: the article reveals the modern understanding of the information and educational environment in the framework of the specifying criteria of the new federal state educational standards for primary general educational ( FSES PGE). The analysis of modern educational electronic 
resources in the open access on the Internet, suitable for use by primary school teachers.

Keywords: information and educational environment (IEE), electronic information and educational environment (EIEE), online platforms, educational portals, communication platforms, interactive whiteboards.

По поручению Президента РФ 27 февраля 2019 года были обновлены ФГОС и примерные ООП с учетом приоритета научнотехнологического развития Российской Федерации, Приказа № 294, п. 2a-16. [1, с. 8]. 31 мая 2021 года были приняты два стандарта ФГОС НОО и ФГОС ООО. В новых версиях ФГОС детально расписано понятие Информационно-образовательная среда (ИОС).Сравнивая компоненты понятия Информационно-образовательная среда, мы видим, что в действующем стандарте ИОС рассматривается как информационная инфраструктура. В новом же стандарте статья 34.3, ИОС рассматривается как доступ к базам данных каждой отдельной образовательной организации.

По ФГОС НОО от 31.05.2021г. выделяют два вида доступа:к учебным планам, рабочим программам учебных предметов, учебных курсов (в том числе внеурочной деятельности), учебных модулей, учебным изданиям и образовательным ресурсам, указанным в рабочих программах учебных предметов, учебных курсов (в том числе внеурочной деятельности), учебных модулей, информации о ходе образовательного процесса, результатах промежуточной и итоговой аттестации обучающихся[2, с. 21];к информации о расписании проведения учебных занятий, процедурах и критериях оценки результатов обучения [2, с. 22].

При этом Информационно-образовательная среда дополняется новым понятием - Электронная информационно-образовательная среда (ЭИОС). Этому посвящена статья 34.4 ФГОС $\mathrm{HOO}$ от 31.05.2021г, в ней мы видим пять составляющих этого понятия. Часть критериев частично или в новом ключе, переходят с первоначального определения Информационно-образовательная среда.

Подробно рассматривая статью 34.4 обратим внимания, что:в ЭИОС образовательной организации входят те информационные и электронные образовательные ресурсы, которыми школа пользуется во время образовательного процесса;-к комплексу используемых образовательных электронных ресурсов у каждого младшего школьника должен быть личный авторизованных вход в течение всего периода обучения и доступ для их родителей;- возможности ЭИОС 
создают условия по освоению образовательных программ начального образования полностью, независимо от места нахождения обучающихся, главное ученику иметь доступ к Интернету. Какие информационные и электронные образовательные ресурсы может использовать сейчас учитель начальных классов? В стандарте указано обязательное соблюдение условия - использование образовательных платформ, которые позволяют в полном объеме освоить ООП НОО.

Сделав обзор современных образовательных электронных ресурсов в открытом доступе сети Интернет, мы выделили три группы сайтов:

для подготовки к уроку. В эту группу входят электронные платформы, из которых учитель берет информацию, перерабатывает её и итоговый материал применяет в объяснении темы.

- для индивидуального выполнения задания. Данная группа подразумевает применение платформ с личным доступом каждого ученика, для оценки и анализа понимания темы слушателей урока.

- $\quad$ для обмена информацией и связи во время урока. К третьей группе мы отнесли платформы позволяющие провести онлайн-урок и ресурсы с возможностями файла обмена.

Опираясь на статью стандарта, об электронной информационно образовательной среде школы, выделим две последние группы, которые выполняют критерий индивидуального входа в электронное образовательное пространство.Детализируя собранную информацию по электронным образовательным ресурсам, в группу «для индивидуального выполнения задания» мы включили:

Онлайн школы - это электронные платформы, через которую ведут образовательную деятельность с применением дистанционной технологии. Есть бесплатный контент, такой как Российская электронная школа и Московская электронная школа, но чаще это платные ресурсы такие как Фоксфорд, Internetypoк, 1С:урок, Учи.ДОМА.В них для помощи учителю есть бесплатный доступ к библиотеке учебников, либо к небольшому количеству заданий.

Специализированные образовательные порталы - это платформы, через которые ведется индивидуальное выполнения заданий по конкретному предмету (Maths-Whizz, Азбука (https://www.bomoonlight.ru/azbuka/), МетаШкола, Русский на 5 , СДАМ ГИА:РЕШУ ВПР, Олимпиада.ru,), либо по определенному учебно-методическому комплекту (УМК) LECTA.

Онлайн-платформы - это цифровые образовательные ресурсы, имеющие небольшую, но концентрированную теоретическую базу по каждому предмету и каждой теме с проверочными заданиями к 
ней, что позволяет индивидуально проверить усвоение урока учеником. Бесплатный контент Яндекс. Учебник, частично-платные: Якласс и Учи.ру. Группа «для обмена информации и связи во время урока»: Коммуникационные платформы - это платформы для организации учебного процесса, в урочное и внеурочное время, которая коммуницирует всех участников. Через эти программы можно создавать чаты и общаться с детьми и их родителями, обмениваться файлами, проводить онлайн уроки, нет ограничения по времени для видео-уроков. Бесплатные версии Сферум и ClassDojo. Для работы на этих платформах необходимо официальное включение всей школы.

Программы для видеоконференций. С развитием дистанционной технологии обучения появилось много программ для проведения видеоконференции, самые популярные среди них: Zoom (бесплатно до 100 чел. до 40 минут), Discord, Skype, Google Meet (бесплатно до 100 чел. до 60 минут).Интерактивные доски онлайн это электронные доски, которые можно применять во время занятий проектной деятельностью либо во время онлайн урока.

Отправляете заранее специальную ссылку каждому ученику и начинается совместная работа на этой доске. (sBoard, miro, Whiteboard Fox, GroupBoard).Можно сделать вывод, что переход к цифровой экономике повышает требования к результативности образования, а следовательно и к трансформации информационно образовательной среды. Это очередной неизбежный этап обновления школы, в которой расширяются границы привычной классно урочной системы.

\section{Список использованных источников}

1. Богуславский, M. Стандарт в России [Текст] / M. Богуславский// Учительская газета. - 2019. - 26 мар. - С.8

2. Официальный интернет-портал правовой информации: [Электронный ресурс] сайт . - 2021. - URL: http://publication.pravo.gov.ru/Document/View/000120210705002 8? index=22\&rangeSize=1 (дата обращения:24.10.2021).

3. ФГОС: Национальная ассоциация развития образования и науки: [Электронный ресурс] сайт. - 2020. - URL: https://fgos.ru/fgos/fgos-noo/(дата обращения:24.10.2021).

(C) Богомазова А.Е., 2021

(C) Гурова Е.В., 2021 